http://jmscr.igmpublication.org/home/ ISSN (e)-2347-176x ISSN (p) 2455-0450 crossref DOI: https://dx.doi.org/10.18535/jmscr/v8i9.46

\title{
Early Detection of Caesarean Scar Ectopic pregnancy-A Case Report
}

\author{
Authors \\ Bala Bharathi ${ }^{1}$, Kurinjiselvan ${ }^{2}$, Amarnath $^{3}$ \\ ${ }^{1}$ Post Graduate, ${ }^{2,3}$ Assistant Professor \\ Department of Radiology, Rajah Muthiah Medical College and Hospital, Chidambaram
}

\begin{abstract}
Caesarean scar ectopic is one of the rarest of all ectopic pregnancies. Although rare, the incidence is increased due to number of caesarean section is more now a days and by implantation of blastocyst on a previous Caesarean scar. This study presents a case of a rare scar ectopic pregnancy in a young female and the importance of early diagnosis and treatment. Ultrasound is the primary imaging modality and place a very important role in recognising and providing proper early diagnosis. If untreated these can have serious complication for the patient including bleeding, rupture of uterus and maternal death.

Keywords: Cesarean scar pregnancy, Beta HCG, TVS, MRI, CSP.
\end{abstract}

\section{Case Summary}

A 25 years old gravid 4 para 2 woman had come for routine antenatal check up after 2 months of amenorrhea and positive urine pregnancy test. No other complaints. Her gestational age was 10 weeks 1 day and was adviced to do ultrasound. Her Medical history revealed one previous cesarean section at term gestation and one dilatation and curettage for missed abortion in early pregnancy.

\section{Imaging Findings}

Her ultrasound findings were-uterus Anteverted, Gestational sac was not seen in the uterine cavity. Endometrial thickness was $4.7 \mathrm{~mm}$. Gestational and yolk sac were seen in lower anterior myometrium with hyperechoic rim of choriodecidual reaction. Gestational sac measured $0.92 \mathrm{~cm}$ corresponding to 4 weeks 5 days. Fetalpole was not seen .Cervical length $3.6 \mathrm{~cm}$. Right and Left ovary appeared normal with follicles. On Doppler examination- superior pole of sac showed vascularity. Hence Scar pregnancy was suspected and adviced to correlate with beta HCG value. Her beta HCG value was $7510 \mathrm{mIU} / \mathrm{ml}$ (normal value at 2-3 months-30,000$1,00,000)$ and it was elevated.

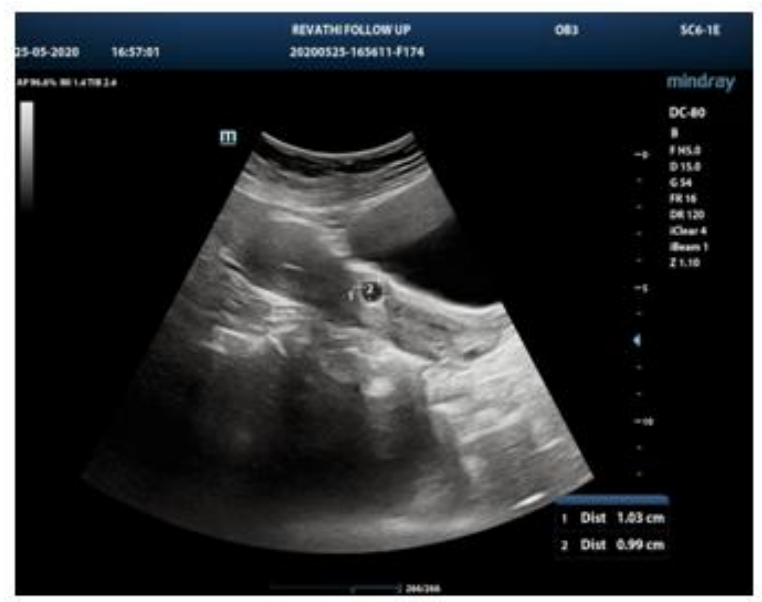

Fig-1: Transabdominal gray scale sonogram ectopic gestational sac in scar region. 


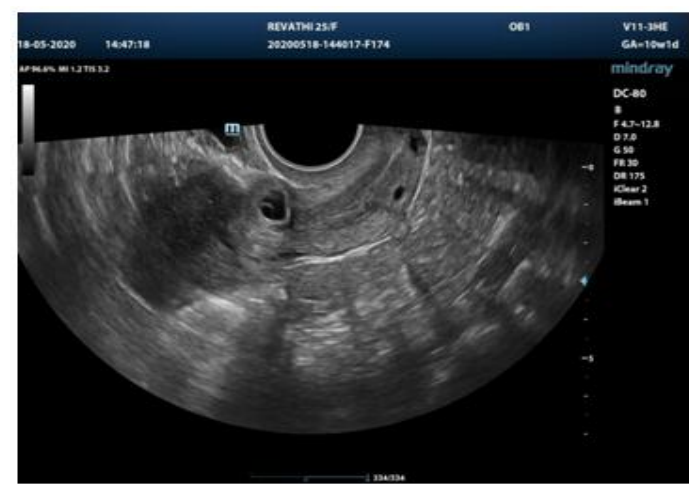

Fig-2: Transvaginal gray scale sonogram showing a gestational sac with yolk sac in the proximity of the scar from a previous cesarean section.

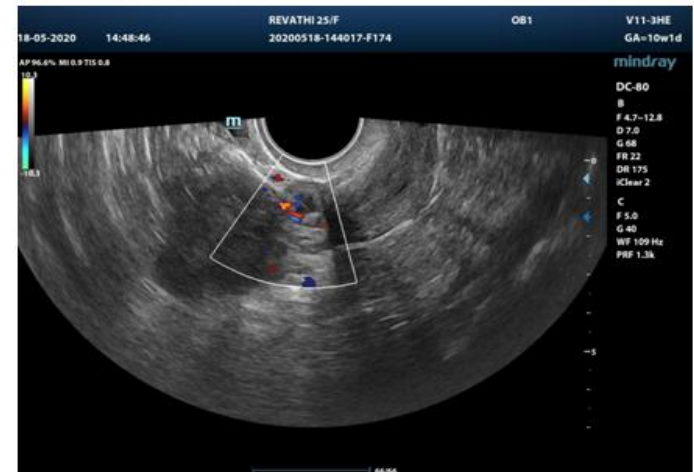

Fig-3: Transvaginal Doppler study showing vascularity seen around the sac.

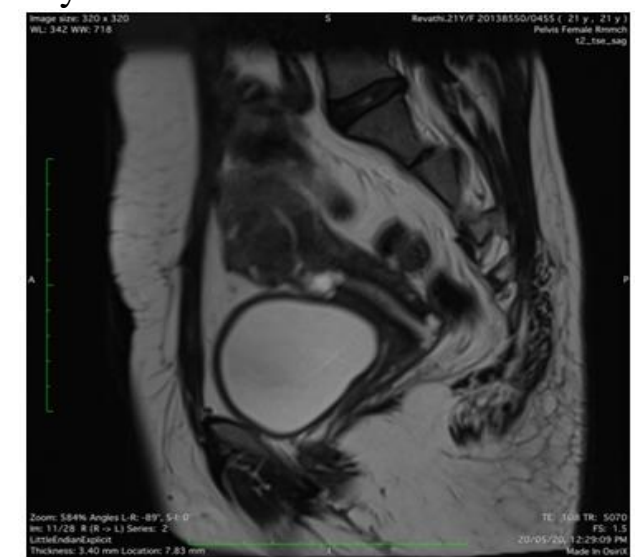

Fig-4:

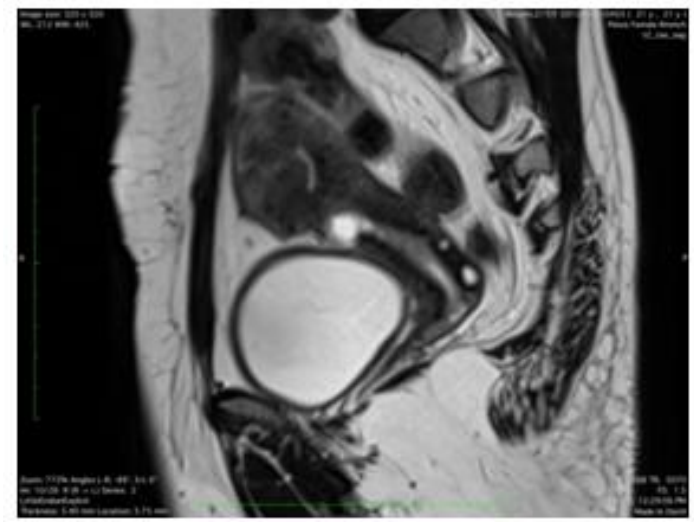

Fig-5:

Fig-4, Fig-5 T2 weighted MRI, sagittal plane showing Ectopic gestation sac present in the anterior myometrial defect
For confirmation MRI was taken. Findings in MRI was - In sagittal T2 weighted images showed gestational sac measuring $1 \times 0.8 \mathrm{~cm}$ noted in the region of previous caesarean scar area. The sac was surrounded by well appreciated decidual reaction. No fetal pole was noted. Anterior myometrium, anterior to gestational sac was thinned out. Posteriorly, gestational sac seemed to be indenting the endometrial cavity. Posterior myometrium showed good wall thickness. No evidence of any invasion into urinary bladder was noted. Follicles were noted in both ovaries. Confirmed in MRI as Ectopic Scar Pregnancy.

Ultrasound guide methotrexate injection was planned. On 21-08-2020, $25 \mathrm{mg}$ (1ml) of methotrexate was injected into the gestational sac under USG guidance and also $25 \mathrm{mg}$ of methotrexate was given intramuscularly. Patient was followed up by serial serum beta HCG values. Her values decreased as follows- $2180 \mathrm{mIU} / \mathrm{ml}$ on 2nd day, $920 \mathrm{mIU} / \mathrm{mi}$ on $7^{\text {th }}$ day, $224 \mathrm{mIU} / \mathrm{ml}$ on $9^{\text {th }}$ day of methotrexate injection. Hence the patient was treated conservatively.

\section{Diagnosis}

Ectopic Scar pregnancy. Grade II

\section{Discussion}

Cesarean scar ectopic pregnancy is the rarest forms of ectopic pregnancies. Its prevalence is estimated between 1 per 1800 and 1 per 2226 pregnancy. Diagnosis of a cesarean scar pregnancy requires a high index of clinical suspicion, as up to $40 \%$ of patients may be asymptomatic. ${ }^{(1)}$

The incidence of cesarean scar pregnancy is rising due to increased incidence of cesarean sections, pelvic inflammatory disease and dilatation and curettage. $^{(2)}$

This is due to the blastocyst implantation into the myometrium through a microscopic dehiscent tract, which may be the result of trauma of a previous caesarean section or any other uterine surgery ${ }^{(3)}$ or even after manual removal of the placenta $^{(4)}$. Another cause for ectopic implantation 
may be in vitro fertilization and embryo transfer also.

Sonographic criteria proposed by Vial et al., are (i) Atrophoblast should implant at cesarean section scar site. (ii) A gestational sac which is ovoid and regular in shape. (iii) A thinned myometrium anteriorto the sac. (iv) on color Doppler-Vascularity to be seen around the sac. (v)A negative "sliding organ sign" helps to differentiate a CSP from a spontaneous abortion in progress. (vi) Pulsed Doppler Findings -high velocity (peak velocity $>20 \mathrm{~cm} / \mathrm{sec}$ ) and low impedance (pulsatility index $<1$ ) waveforms.

Two types of CSPs have been proposed by Vial et $a l .$, (i)Implantation at cesarean scar with inward growth. (ii)Deep implantation in the scar with outward growth ${ }^{(5)}$. Hemorrhageis common in first type and second type is associated with greater risk of rupture ${ }^{(6)}$. MRI helps in localization of the ectopic sac and its relationship with adjacent organs, myometrial invasion and bladder involvement. Therefore, it provides very important information in determining the treatment plan. ${ }^{(7)}$ Four grades of CSP noted. GradeI: GS embedded in less than half thickness of the lower anterior myometrium; grade II: GS extended to more than half thickness of overlying myometrium. Grade III: GS bulged out of the cesarean scar; grade IV: GS became an amorphous tumor with rich vascularity at the cesarean scar. This type of pregnancy is prone for complications like uterine rupture, life threatening hemorrhage, and hypovolemic shock. ${ }^{(8)}$ New advent saline sonohysterogram, we can to assess uterine wall integrity at previous LSCS scar area even in the nonpregnant state. ${ }^{(9)}$ Scar defect is identified by the presence of fluid within the incision site ${ }^{(10)}$ or any filling defect ("niche"), which is defined as a triangular anechoic structure at the presumed site of the scar. ${ }^{(11)}$

Differential diagnosis of CSP includes early placenta accrete, incomplete abortion and cervical pregnancy.

\section{Conclusion}

Cesarean pregnancy is the rarest form of ectopic pregnancy. It increases in frequency due to increased incidence of cesarean deliveries, dilatation and curettage. It is one of commonest cause of hemorrhage in first trimester, so early diagnosis is very important. Due to extensive availability of Trans vaginal ultrasound and high clinical suspicion, it is possible now a days. Absence of sac in uterine cavity and sac like structure in lower uterine segment indicates it an ectopic pregnancy.MRI is most commonly used to confirm the diagnosis, to know the myometrial invasion and also prognosis. So early diagnosis helps in salvaging uterus by conservative treatment.

\section{References}

1. Rotas MA, Haberman S, Levgur $M$. Cesarean scar ectopic pregnancies: Etiology, diagnosis and management. Obstet Gynecol. 2006; 107: 1373-81. [PubMed] [Google Scholar]

2. Timor-Tritsch IE, Monteagudo A (2012) Unforeseen consequences of the increasing rate of cesarean deliveries: early placenta accreta and cesarean scar pregnancy. A review. Am J Obstet Gynecol 207: 14-29.

3. P.J. Cheng, H.Y. Chueh, Y.K. Soong Sonographic diagnosis of a uterine defect in a pregnancy at 6 weeks gestation with a history of curettage Ultrasound Obstet Gynecol, 21 (2003), pp. 501-503.

4. D.L. Fylstra Ectopic pregnancy within a Caesarian scar: a review Obstet Gynecol Surv, 57 (2002), pp. 537-543

5. C.J. Hamilton, J. Legarth, K.A. Jaroudi Intramural pregnancy after in vitro fertilization and embryo transfer Fertil Steril, 57 (1992), pp. 215-217

6. Vial Y, Petignat P, Hohlfeld P. Pregnancy in a cesarean scar. Ultrasound Obstet Gynecol. 2000; 16:592-3. [PubMed] [Google Scholar]) 
7. Bozkurt DK, Bozkurt M, Sahin L (2014) Magnetic Resonance Imaging in Addition to Ultrasound in the Diagnosis of Cesarean Scar Ectopic Pregnancy. J Med Cases 5: 329-333.

8. D. Jurkovic, K. Hillaby, B. Woelfer, A. Lawrence, R. Salim, C.J. ElsonFirsttrimester diagnosis and management of pregnancies implanted into the lower uterine segment Caesarian section scar Ultrasound Obstet Gynecol, 21 (2003), pp. 220-227

9. A. Ravhon, A. Ben Chetrit, R. Rabinowitz, M. Neuman, U. Beller Successful methotrexate treatment of a viable pregnancy within a thin uterine scar $\mathrm{Br} \mathrm{J}$ Obstet Gynecol, 104 (1997), pp. 628-629.

10. V. Armstrong, W.F. Hansen, B.J. Van Voorhis, C.H. Syrop Detection of Caesarian scars by transvaginal ultrasound. Obstet Gynecol, 101 (2003), pp. 61-65.

11. A. Monteagudo, C. Carreno, I.E. TimorTritsch Saline infusion sonohysterography in non pregnant women with previous Caesarian delivery: the 'niche' in the scar. J Ultrasound Med, 20 (2001), pp.11051115 . 